\title{
Baicalin alleviates lipopolysaccharide- induced neuroglial activation and inflammatory factors activation in hippocampus of adult mice
}

\author{
Murad-Ali Shah ${ }^{1 \dagger}$, Dong-Ju Park ${ }^{1 \dagger}$, Ju-Bin Kang ${ }^{1}$, Myeong-Ok Kim² and Phil-Ok Koh ${ }^{1 *}$ (1)
}

\begin{abstract}
Baicalin is a natural flavonoid that exerts a variety of pharmaceutical effects such as anti-inflammatory and antioxidant. Lipopolysaccharide (LPS) is an endotoxin that releases inflammatory cytokines and induces inflammatory response. This study was investigated the anti-inflammatory mechanism of baicalin against LPSinduced inflammatory response in the hippocampus. Adult mice were randomly grouped into control, LPS-treated, and LPS and baicalin co-treated animals. LPS $(250 \mu \mathrm{g} / \mathrm{kg} /$ day $)$ and baicalin $(10 \mathrm{mg} / \mathrm{kg} /$ day $)$ were administered intraperitoneally for 7 consecutive days. We measured neuroglia cells activation and inflammatory factors activation using Western blot analysis and immunofluorescence staining techniques. lonized calcium binding adaptor molecule-1 (Iba-1) and glial fibrillary acidic protein (GFAP) are widely used as microglia and astrocyte markers, respectively. LPS treatment increased Iba-1 and GFAP expression, while baicalin co-treatment attenuated this overexpression. Nuclear factor-kappa B (NF-KB) is a key mediator of inflammation. Baicalin co-treatment alleviated LPS-induced increase of NF-KB in the hippocampus. In addition, LPS treatment upregulated pro-inflammatory cytokines including interleukin-1 $\beta$ (IL-1 $\beta$ ) and tumor necrosis factor-a (TNF-a). However, baicalin co-treatment prevented LPS-induced increases of IL-1 $\beta$ and TNF- $\alpha$ in the hippocampus. Results from the present study showed that baicalin suppresses LPS-induced neuroinflammation by regulating microglia and astrocyte activation and modulating inflammatory factors in the hippocampus. Thus, these results demonstrate that baicalin has neuroprotective effect by alleviates microglia and astrocyte activation and modulates inflammatory response by suppressing NF-kB expression in hippocampus with neuroinflammation caused by LPS.
\end{abstract}

Keywords: Baicalin, Hippocampus, Lipopolysaccharide, Neuroinflammation

\footnotetext{
* Correspondence: pokoh@gnu.ac.kr

${ }^{+}$Murad-Ali Shah and Dong-Ju Park contributed equally to this work.

'Department of Anatomy, College of Veterinary Medicine, Research Institute of Life Science, Gyeongsang National University, 501 Jinjudaero, Jinju 52828, South Korea

Full list of author information is available at the end of the article
}

(c) The Author(s). 2020 Open Access This article is licensed under a Creative Commons Attribution 4.0 International License, which permits use, sharing, adaptation, distribution and reproduction in any medium or format, as long as you give appropriate credit to the original author(s) and the source, provide a link to the Creative Commons licence, and indicate if changes were made. The images or other third party material in this article are included in the article's Creative Commons licence, unless indicated otherwise in a credit line to the material. If material is not included in the article's Creative Commons licence and your intended use is not permitted by statutory regulation or exceeds the permitted use, you will need to obtain permission directly from the copyright holder. To view a copy of this licence, visit http://creativecommons.org/licenses/by/4.0/ The Creative Commons Public Domain Dedication waiver (http://creativecommons.org/publicdomain/zero/1.0/) applies to the data made available in this article, unless otherwise stated in a credit line to the data. 


\section{Introduction}

Inflammation is considered a defense response against infection or injury and an important feature for the treatment of infectious disease. Lipopolysaccharide (LPS) is a bacterial endotoxin that is found in gram-negative bacteria [1]. LPS activates neuroglial cells and induces the inflammatory response in the nervous system. Administration of LPS causes inflammation in brain tissue and subsequently leads to neuronal dysfunction [2]. Inflammation with bacterial infection leads to neurological diseases such as Parkinson's disease [3]. In addition, LPS induces inflammation in many tissues including liver and lung [4, 5]. Inflammation is regulated by several inflammatory mediators such as cytokines and chemokines [6, 7]. LPS induces pro-inflammatory cytokines and leads to inflammatory response and cell death [8]. Pro-inflammatory cytokines act as critical factors in neuroinflammation and neurodegeneration processes of neurodegenerative diseases $[9,10]$.

Baicalin is a flavonoid compound derived from the roots of Scutellaria baicalensis Georgi and exerts a variety of beneficial effects in the central nervous system and immune system [11]. Baicalin has antioxidant, antiinflammatory, anti-cancer, as well as anti-apoptotic properties and exerts neuroprotective effects on global cerebral ischemia and reperfusion models [12-14]. Baicalin improves the spatial learning ability by reducing hippocampal apoptosis. In addition, baicalin exerts antiinflammatory effects by inhibiting the production of inflammatory mediators and binding to chemokines [13]. It exhibits anti-inflammatory properties against LPSinduced inflammation by suppressing the nuclear factorkappa B (NF-kB) signaling pathway in HBE16 airway epithelial cells [15]. Moreover, baicalin prevents superantigen-induced inflammatory cytokines and chemokines [16]. Previous studies have been shown the anti-inflammatory and anti-apoptotic effects of baicalin in liver, lung, and kidney injuries [17, 18]. However, little information is demonstrated the anti-inflammatory effects of baicalin against LPS-induced toxicity in the hippocampus. The present study elucidates how baicalin regulates the inflammatory response caused by LPS in hippocampus of adult mice. We examined neuroglia cells activation during LPS-induced damage. This study was also investigated the anti-inflammatory mechanism of baicalin on LPS-induced expressions of NF- $\mathrm{KB}$ and pro-inflammatory factors, such as interleukin- $1 \beta$ (IL-1 $\beta$ ) and tumor necrosis factor- $\alpha$ (TNF- $\alpha)$, in the hippocampus.

\section{Materials and methods}

\section{Experimental animals and drug administration}

Adult male mice (C57BL/6 N, 8 weeks, 31-33 g, $n=30$ ) were obtained from Samtako Co. (Animal Breeding
Center, Osan, Korea). All experimental procedures were carried out according to the guideline of the Institutional Animal Care and Use Committee of Gyeongsang National University. Mice were housed under controlled temperature $\left(23-25^{\circ} \mathrm{C}\right)$ and lighting condition $(12 \mathrm{~h}$ light/ $12 \mathrm{~h}$ dark cycle) with free acess to food and water. Animals were divided into the following three groups: control group, LPS-treated group, LPS and baicalin cotreated group. LPS $(250 \mu \mathrm{g} / \mathrm{kg}$, Sigma Aldrich, St. Louis, MO, USA) was dissolved in normal saline solution and treated by intraperitoneal injection for 7 days. Baicalin (10 mg/kg, Sigma Aldrich) was dissolved in 0.1\% dimethyl sulfoxide with normal saline and co-treated with LPS for 7 days. Vehicle was prepared with same solvent solution without baicalin and treated for consecutive 7 days in control group. Body weight was measured and animals were sacrificed at $24 \mathrm{~h}$ after last injection. Animals were euthanized by cervical dislocation and brain tissues were removed from skull and fixed in $4 \%$ neutral buffered paraformaldehyde (NBP) for immunofluorescence staining $(n=5)$. For Western blot analysis, hippocampal tissues were separated from brain and kept in $-70{ }^{\circ} \mathrm{C}(n=5)$.

\section{Western blot analysis}

Hippocampal tissues were homogenized and sonicated in lysis buffer [1\% Triton X-100, 1 mM EDTA in phosphatebuffered saline (PBS) ( $\mathrm{pH} 7.4$ )]. Homogenates were centrifuged at $15,000 \mathrm{~g}$ for $20 \mathrm{~min}$ and supernatants were collected. Protein concentration was determined by BCA protein analysis kit (Thermo Fischer Scientific, Walthem, MA, USA)). Protein samples $(30 \mu \mathrm{g})$ were separated by $10 \%$ sodium dodecyl sulfate poly-acrylamide gels and transferred to a poly-vinylidene fluoride membrane (Millipore, Billerica, MA, USA). Membranes were incubated with $5 \%$ skim milk solution for $1 \mathrm{~h}$ and washed with trisbuffered saline containing $0.1 \%$ Tween-20 (TBST). They were incubated for overnight at $4{ }^{\circ} \mathrm{C}$ with following primary antibody: mouse anti-ionized calcium binding adaptor molecule-1 (Iba-1), mouse anti-glial fibrillary acidic protein (GFAP), mouse anti-NF- $\mathrm{B}$ p65, mouse anti-TNF- $\alpha$, mouse anti- IL- $1 \beta$, and mouse anti- $\beta$-actin (1:1000, Santa Cruz Biotechnology, Dallas, TX, USA). Membranes were washed with TBST and reacted with horseradish peroxidase-conjugated anti-mouse IgG or antirabbit IgG (1:5000, Thermo Fischer Scientific) for $2 \mathrm{~h}$ at room temperature. They were washed with TBST and incubated with enhanced chemiluminescence reagent (GE Healthcare, Chicago, IL, USA). Immunoreactive protein bands were visualized on X-ray film and analyzed by a Image J (National Institutes of Health, Bethesda, MD, USA).

\section{Immunofluorescence staining}

Fixed brain tissues with $4 \%$ NBP were washed with tap water for overnight. Brain tissues were dehydrated with 
a graded ethanol series (70 to 100\%) and cleaned with xylene. They were embedded with paraffin in embedding center (Leica, Wetzlar, Germany) and blocked with paraffin according to a routine protocol. They were sliced into $4 \mu \mathrm{m}$ thickness coronal section using a rotatory microtome (Leica). Sliced brain tissues were placed on slide glass, deparaffinized with xylene, rehydrated with a graded ethanol series (100 to 70\%), and washed with PBS. They were incubated with normal goat serum for $1 \mathrm{~h}$ to block non-specific binding and reacted for overnight at $4{ }^{\circ} \mathrm{C}$ with following primary antibody: mouse anti-Iba-1, mouse anti-GFAP, mouse anti-NF- $\mathrm{B}$ b 65 , mouse anti-TNF- $\alpha$, and mouse anti-IL-1 $\beta$ (1:100, Santa Cruz Biotechnology). Slides were washed with PBS and incubated with fluorescein isothiocyanate (FITC)-conjugated antimouse IgG (1:200, Santa Cruz Biotechnology) for $2 \mathrm{~h}$ at room temperature. They were washed with PBS and reacted with 4', 6-Diamidino-2-phenylindole (DAPI, Sigma Aldrich) for $10 \mathrm{~min}$ to counterstain nucleus. Slides were mounted with Ultra-Cruz mounting medium (Santa Cruz Biotechnology). Positive signals were observed using a confocal microscope (Flouview FV 1000, Olympus) and photographed. The number of FITC and DAPI double positive cells in hippocampal CA1, CA2 and CA3 areas were counted by blinded experimenter. Counted cell numbers were calculated and expressed as average number of FITC and DAPI double positive cells in each hippocampal area.

\section{Statistical analysis}

All data from the experiment are expressed as mean \pm standard error of mean (S.E.M.). The experiment results in each group were compared by two-way analysis of variance (ANOVA) followed by post-hoc Scheffe's test. A value of $p<0.05$ was regarded as statistically significant.

\section{Results}

We measured body weight as a basic physiological data. LPS reduced body weight, but baicalin attenuated weight loss induced by LPS. Body weights of mice were $31.4 \pm$
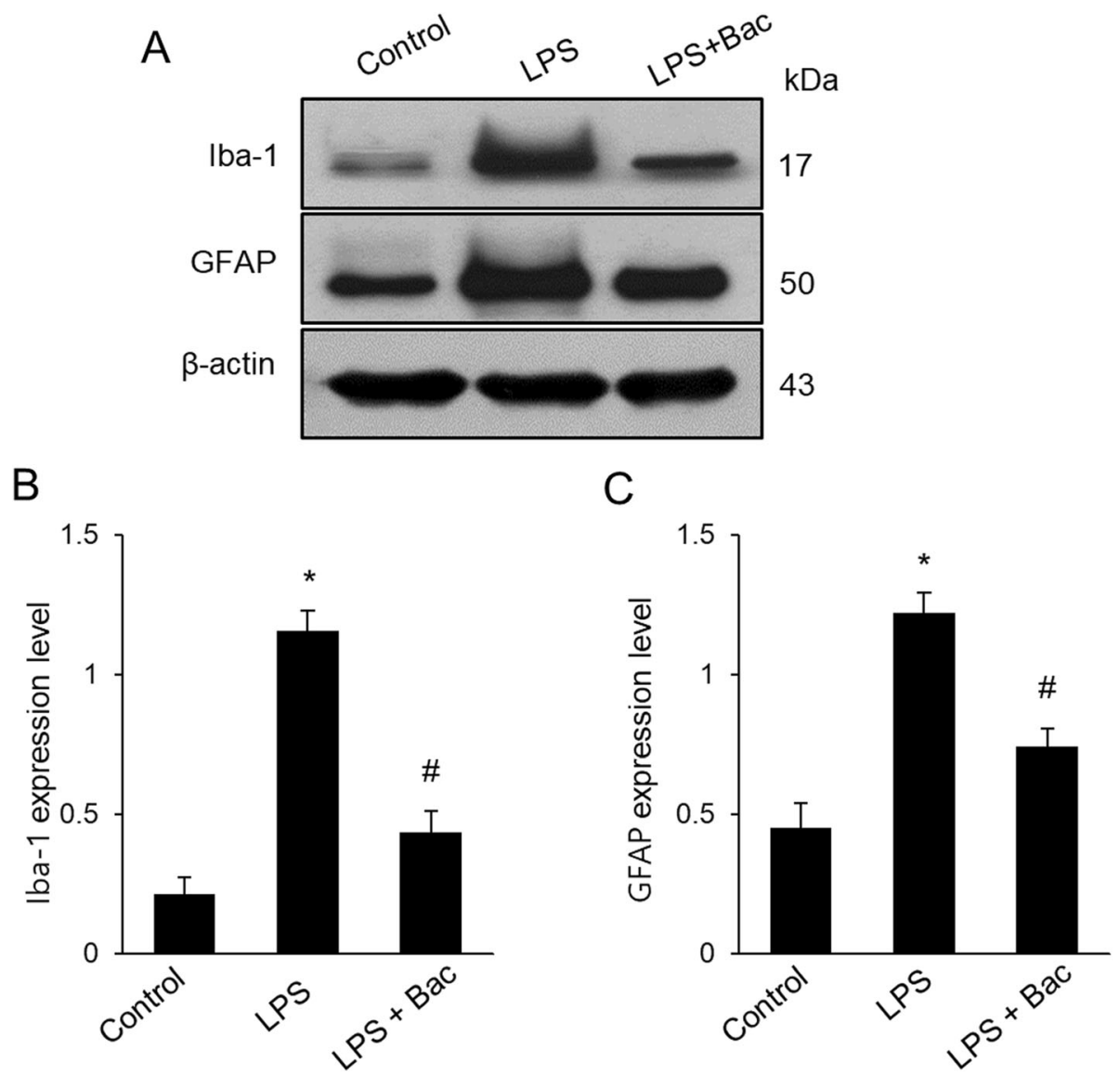

Fig. 1 Western blot analysis of ionized calcium binding adaptor molecule-1 (Iba-1) and glial fibrillary acidic protein (GFAP) in hippocampus of control, lipopolysaccharide (LPS)-treated, and LPS and baicalin (Bac) co-treated animals (a). Density values of Western blot analysis are expressed as a ratio of these proteins intensities to $\beta$-actin intensity $(\mathbf{b}, \mathbf{c})$. Data $(n=5)$ are shown as mean \pm S.E.M. * $p<0.05$ vs. control animal, \# $p<0.05$ vs. LPS-treated animal 
$1.53 \mathrm{~g}$ in the LPS-treated and $35.8 \pm 1.45 \mathrm{~g}$ in baicalin cotreated animals after 7 days injection. Moreover, body weights of the control group were $37.8 \pm 2.45 \mathrm{~g}$. Iba- 1 and GFAP expression was investigated to confirm the activation of microglia and astrocytes in the hippocampus. Increases in Iba-1 and GFAP expression were found in the hippocampus of LPS-treated animals. However, LPS and baicalin co-treatment significantly attenuated LPS-induced increases in Iba-1 and GFAP expression (Fig. 1a). Western blot analysis showed that Iba-1 expression levels were $1.15 \pm 0.07$ and $0.43 \pm 0.06$ in LPStreated and baicalin co-treated animals, respectively (Fig. 1b). In addition, GFAP expression levels were
$1.21 \pm 0.07$ in LPS-treated and $0.74 \pm 0.08$ in baicalin cotreated animals (Fig. 1c). Results from immunofluorescence staining showed increased positive reactions of Iba-1 and GFAP in LPS-treated animals; the increases were significantly attenuated in LPS and baicalin cotreated animals (Figs. 2, 3). These changes appeared in every region including CA1, CA2, and CA3. These changes in the CA1 region are more severe than CA2 and CA 3 regions. In the CA1 region, the number of Iba1 and DAPI double positive cells were $67.6 \pm 4.28$ and $22.2 \pm 1.92$ in LPS-treated and baicalin co-treated animals, respectively (Fig. 2d). Moreover, the number of GFAP and DAPI double positive cells were $66.2 \pm 4.92$ in

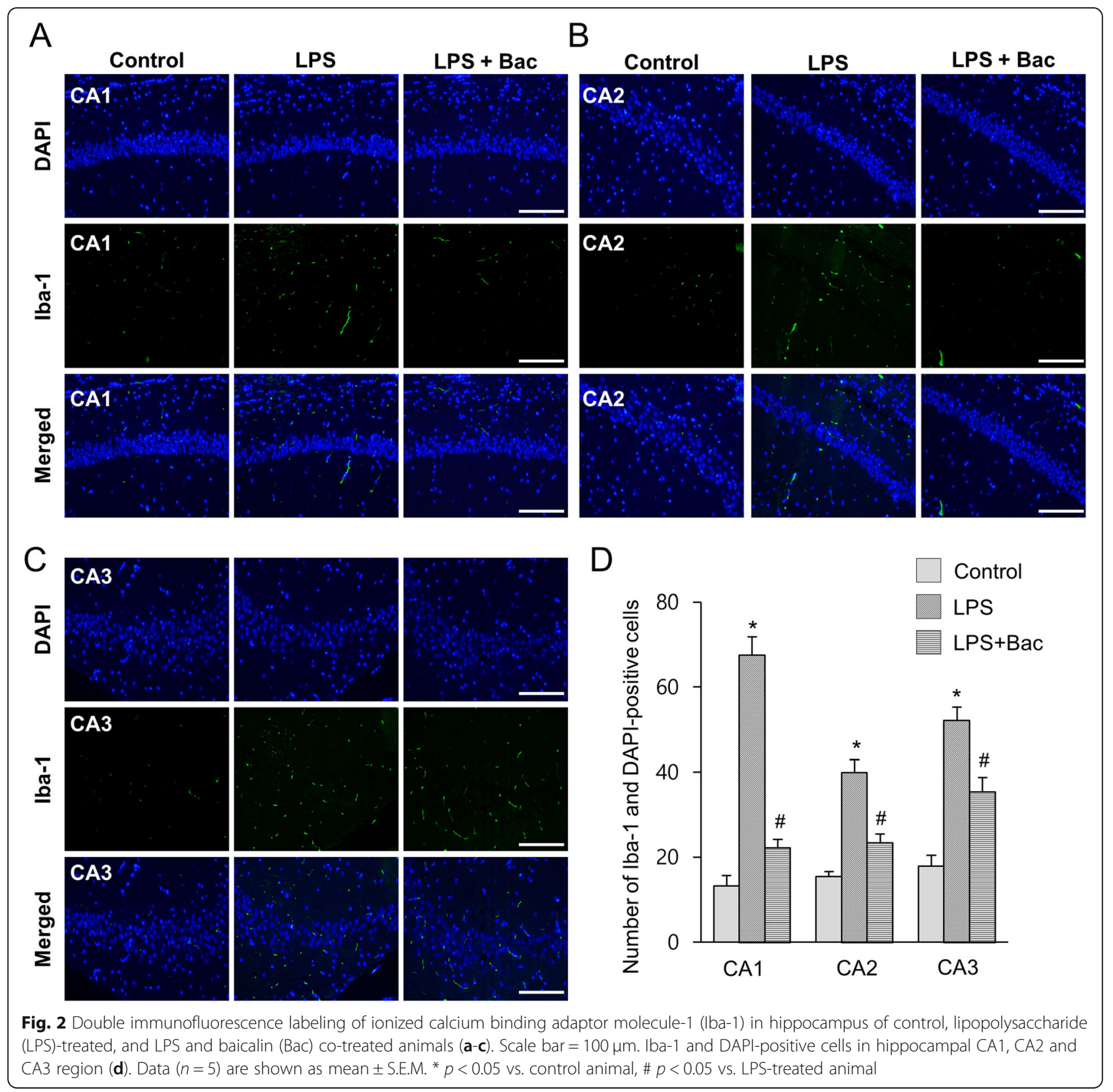




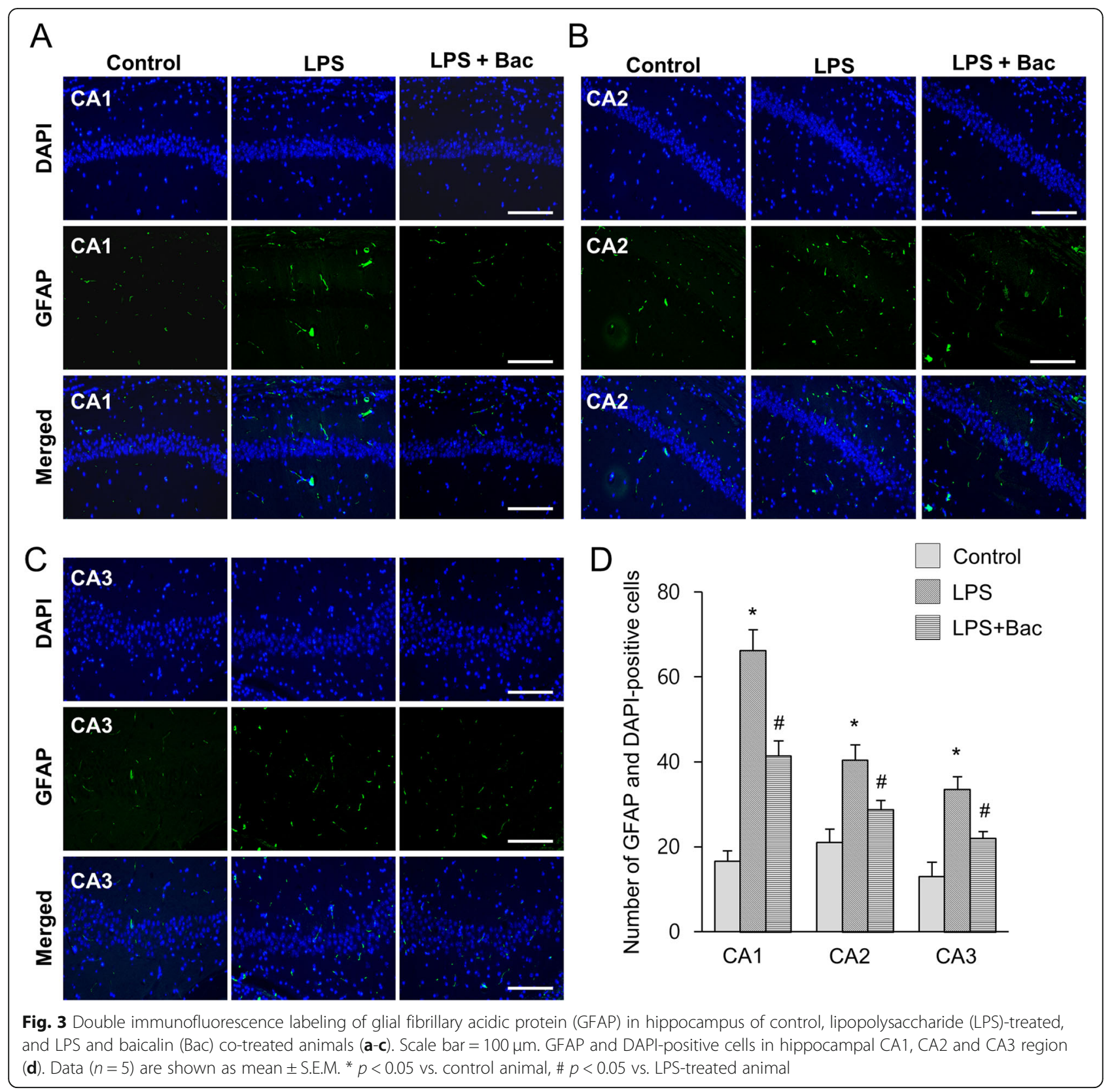

LPS-treated and $41.4 \pm 3.51$ in baicalin co-treated animals (Fig. 3d).

Figure $4 \mathrm{a}$ showed the changes of NF-kB in LPS and baicalin co-treated animals. Western blot analysis showed that NF- $\kappa B$ expression levels were $1.52 \pm 0.07$ and $1.11 \pm 0.04$ in LPS-treated and baicalin co-treated animals, respectively (Fig. 4b). Furthermore, changes of inflammatory cytokines, including IL- $1 \beta$ and TNF- $\alpha$, were observed in LPS and baicalin co-treated animals (Fig. 4a). Results from immunoblotting showed increased IL-1 $\beta$ and TNF- $\alpha$ protein expression levels in the hippocampus of LPS-treated animals. However, LPS and baicalin co-treatment significantly attenuated the increased
IL-1 $\beta$ and TNF- $\alpha$ inflammatory cytokine expression levels. IL-1 $\beta$ expression levels were $1.17 \pm 0.11$ in LPStreated and $0.69 \pm 0.08$ in baicalin co-treated animals (Fig. 4c). TNF- $\alpha$ expression levels were $1.30 \pm 0.06$ and $0.87 \pm 0.13$ in LPS-treated and baicalin co-treated animals, respectively (Fig. 4d). Changes in NF- $\mathrm{kB}, \mathrm{IL}-1 \beta$, and TNF- $\alpha$ levels were confirmed based on immunofluorescence staining results (Figs. 5-7). These results showed a pattern similar to immunoblotting data. These changes were observed in $\mathrm{CA} 1, \mathrm{CA} 2$, and $\mathrm{CA} 3$ regions. NF- $\mathrm{kB}$, IL- $1 \beta$, and TNF- $\alpha$ expressions were more significantly increased in the CA1 region than $\mathrm{CA} 2$ and $\mathrm{CA} 3$ regions. In the CA1 region, the numbers of NF- $\mathrm{KB}$ and 

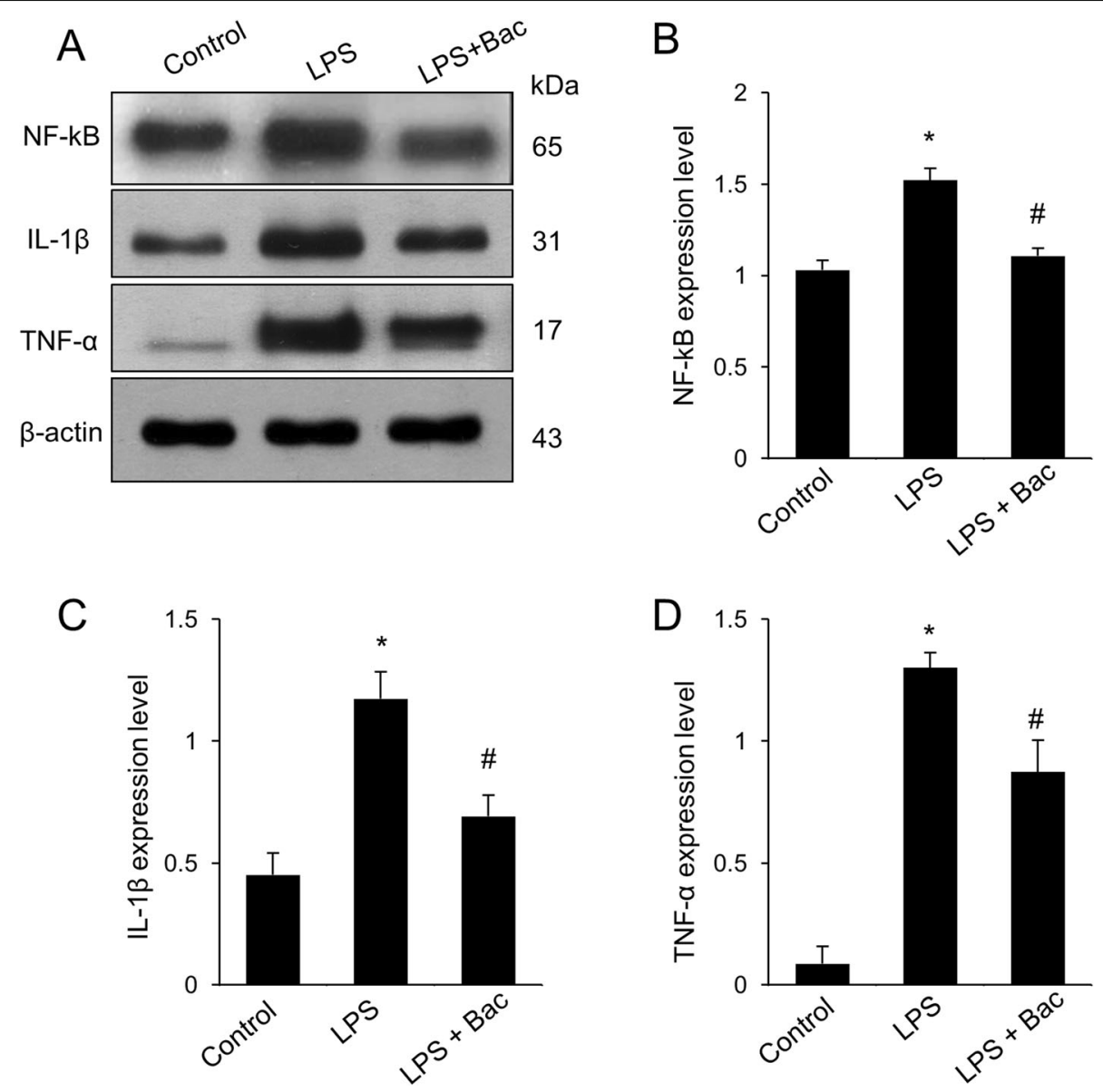

Fig. 4 Western blot analysis of nuclear factor kappa B (NF-KB), interleukin-1 $\beta$ (IL-1 $\beta$ ), and tumor necrosis factor-a (TNF-a) in hippocampus of control, lipopolysaccharide (LPS)-treated, and LPS and baicalin (Bac) co-treated animals (a). Density values of Western blot analysis are expressed as a ratio of these proteins intensities to $\beta$-actin intensity $(\mathbf{b}-\mathbf{d})$. Data $(n=5)$ are shown as mean \pm S.E.M. ${ }^{*} p<0.05$ vs. control animal, \# $p<0.05$ vs. LPS-treated animal

DAPI double positive cells were $59.6 \pm 6.77$ and $29.2 \pm$ 3.96 in LPS-treated and baicalin co-treated animals, respectively (Fig. $5 \mathrm{~d}$ ). The numbers of IL-1 $\beta$ and DAPI double positive cells were $72.4 \pm 6.35$ in LPS-treated and $41.4 \pm 3.51$ in baicalin co-treated animals (Fig. 6d). The numbers of TNF- $\alpha$ and DAPI double positive cells were $61.8 \pm 4.92$ and $36.6 \pm 4.04$ in LPS-treated and baicalin co-treated animals, respectively (Fig. $7 \mathrm{~d}$ ).

\section{Discussion}

Baicalin has anti-inflammatory effects against various inflammatory diseases [13]. Our results confirmed the anti-inflammatory property of baicalin against LPStreatment in hippocampal tissues of adult mice. Systemic administration of LPS leads to activation of microglia and astrocytes [19, 20]. Activated microglia causes the production of pro-inflammatory cytokines leading to neuroinflammation and neurodegeneration [10]. Baicalin exerts an anti-inflammatory effect by suppression of inflammasome activation in LPS-exposed piglet mononuclear phagocytes [21]. LPS activates generation of pro-inflammatory cytokines and induces neuroinflammation and neurodegeneration [22]. LPS leads to activation of microglia and astrocytes in the hippocampus. Iba-1 and GFAP are used as markers of activated microglia and astrocytes [23]. Moreover, baicalin attenuated LPS-induced increases in Iba- 1 and GFAP expression in the hippocampus. Our results indicated that baicalin alleviates LPS-induced activation of microglia and astrocytes in the hippocampus. Iba-1 acts as an adaptor molecule facilitating calcium signals and abundantly exists in microglia and macrophages [24]. It is significantly upregulated in activated microglial cells [25]. In addition, GFAP is a filamentous protein in astrocytes and involved in the structure and function of the cell cytoskeleton. GFAP contributes to the mechanical strength and shape of cells, formation of the blood-brain barrier, and communication of cells. GFAP-knockout mice displayed abnormal myelination and impaired blood-brain barrier [26]. Baicalin alleviated LPS-induced increase in GFAP 


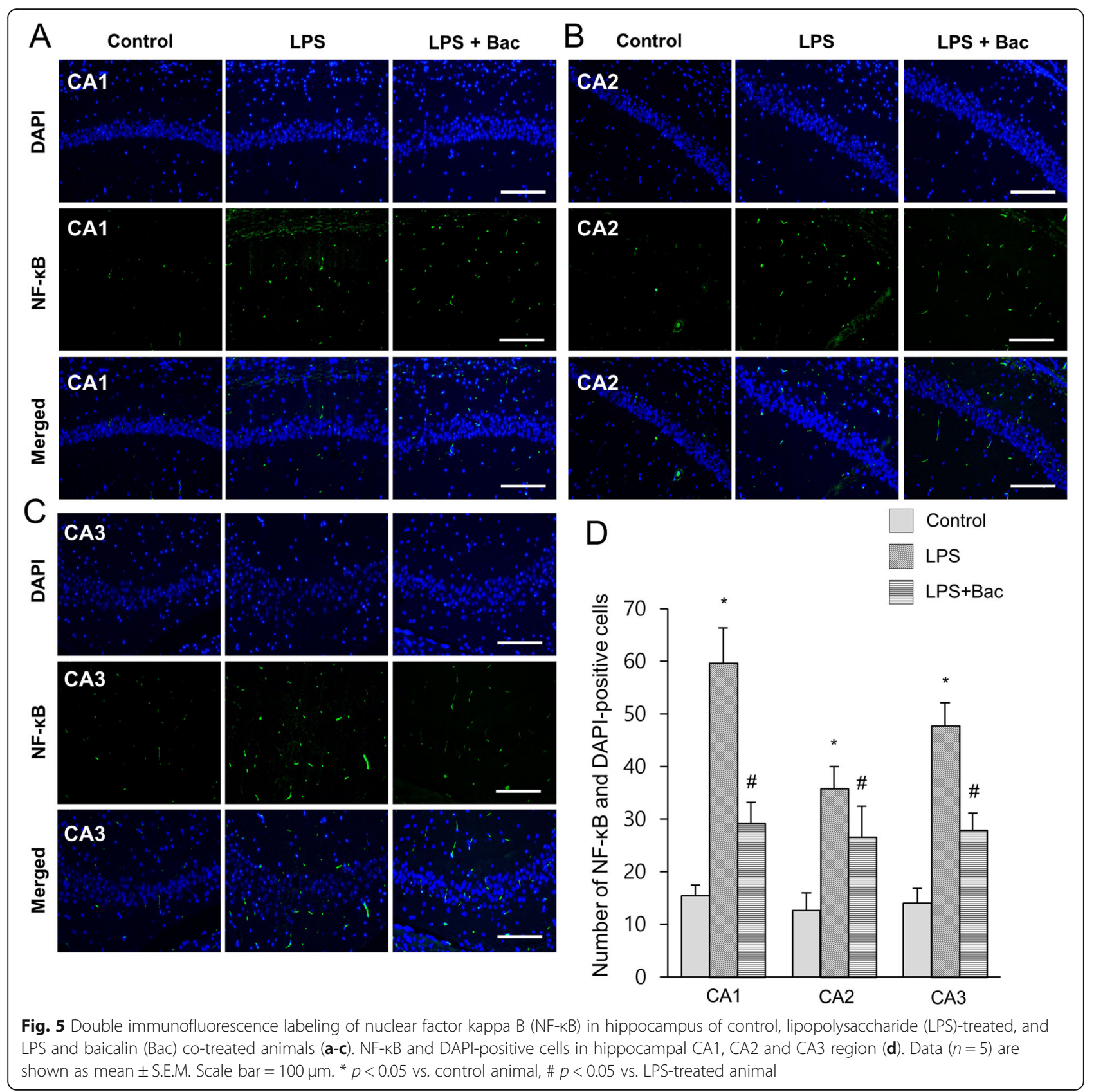

expression. Our results from the present study showed that baicalin prevents increased Iba-1 and GFAP expression levels caused by LPS in the hippocampus, suppresses activation of microglia and astrocytes, and modulates neuroinflammation.

Inflammation is a protective immune mechanism against infection caused by foreign organisms, such as bacteria and viruses. However, excessive inflammatory response leads to systemic dysfunction and tissue damage, finally causing cell death. Macrophages have an important role in initiation and maintenance of inflammation and production of pro-inflammatory cytokines [27, 28]. Pro-inflammatory cytokines, such as TNF- $\alpha$ and IL- $1 \beta$, are critical factors in pathogenesis of the inflammatory response. In addition, the inflammatory response is a pathological process which can cause many inflammatory diseases and regulated by the NF- $\mathrm{KB}$ signaling pathway [29]. NF- $\mathrm{kB}$ is a protein complex that regulates DNA transcription, cytokine production, and cell survival. NF-kB plays a critical role in modulating the immune response to infection. Abnormal modulation of NF- $\mathrm{kB}$ is associated with inflammatory and autoimmune diseases, viral infection, and improper immune development. NF- $\mathrm{kB}$ is activated by exposure of various 


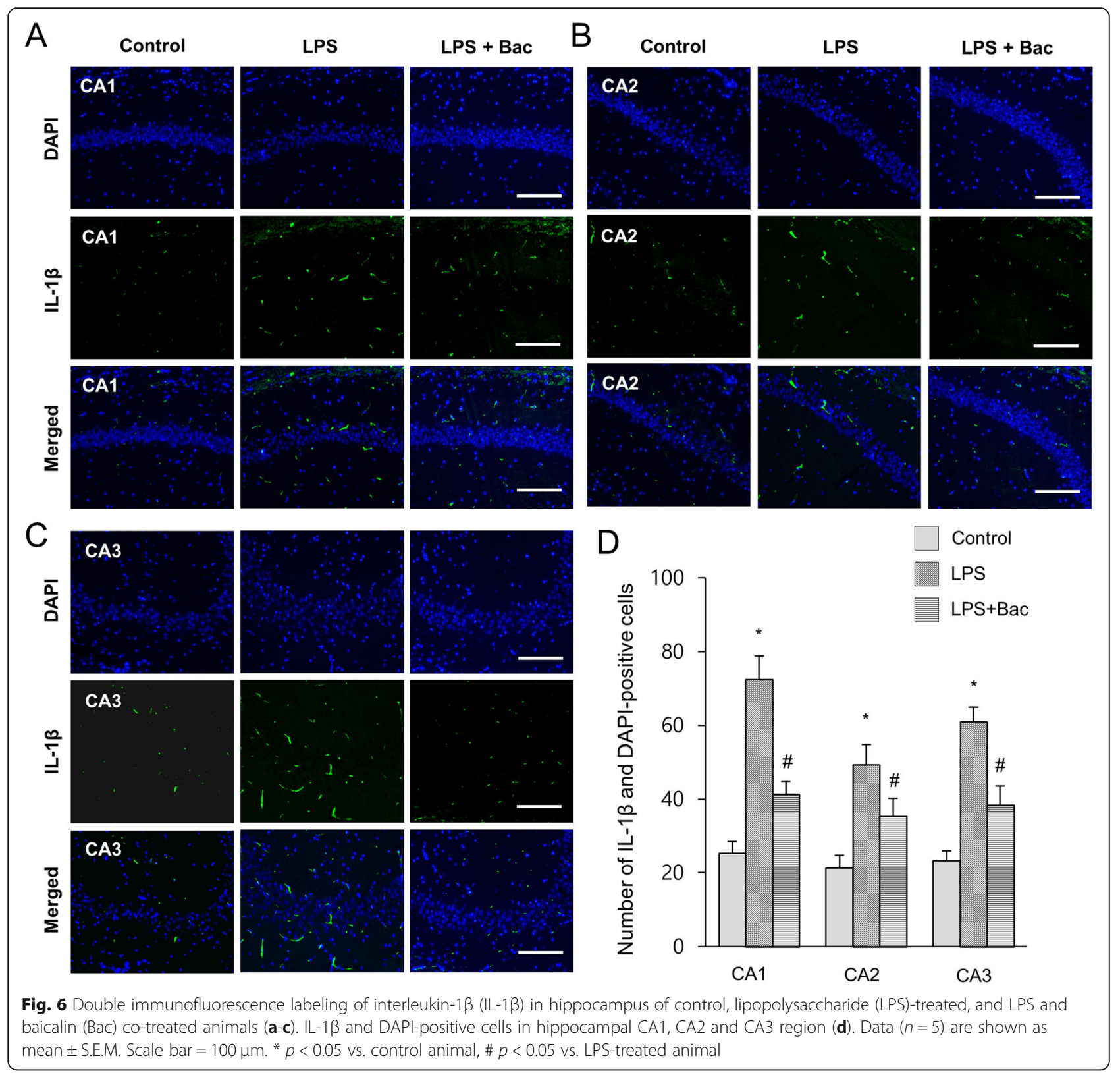

inflammatory cytokines such as TNF- $\alpha$, IL- $1 \beta$, and oxidative stress [30, 31]. LPS leads to the activation of proinflammatory mediators and causes neuroinflammation [32]. In the present study, LPS contributed to upregulation of NF- $\mathrm{kB}$ in the hippocampus and baicalin cotreatment mitigated the increase of NF- $\mathrm{kB}$. These results showed that baicalin attenuates the LPS-induced neuroinflammation by regulating NF- $\mathrm{kB}$ expression.

IL-1 $\beta$ belongs to the interleukin-1 family and is a major mediator of inflammation [33]. IL-1 $\beta$ is synthesized in various cells including monocytes, macrophages, and neutrophils. IL-1 $\beta$ binds to interleukin 1 receptor, initiates a cascade of inflammatory cytokines and chemokines, and results in the inflammatory response [34].
LPS increases the expression of IL-1 $\beta$ in bronchial epithelial cells and umbilical vein endothelial cells [35]. Our results showed LPS induces IL- $1 \beta$ production in the hippocampus. LPS treatment is associated with memory deficit, anxiety, depression, and neuroinflammation [36]. IL- $1 \beta$ acts as a key mediator in LPS-induced dysfunction of hippocampal neurons [37]. IL-1 $\beta$ knockdown significantly attenuated the memory deficits and anxiety- and depression-like behaviors caused by LPS. In addition, IL$1 \beta$ knockdown ameliorated LPS-induced neuroinflammatory responses and abolished the downregulation of brain-derived neurotrophic factor [38, 39]. Our results showed that upregulation of IL- $1 \beta$ expression by LPS administration was attenuated by baicalin co-treatment in 


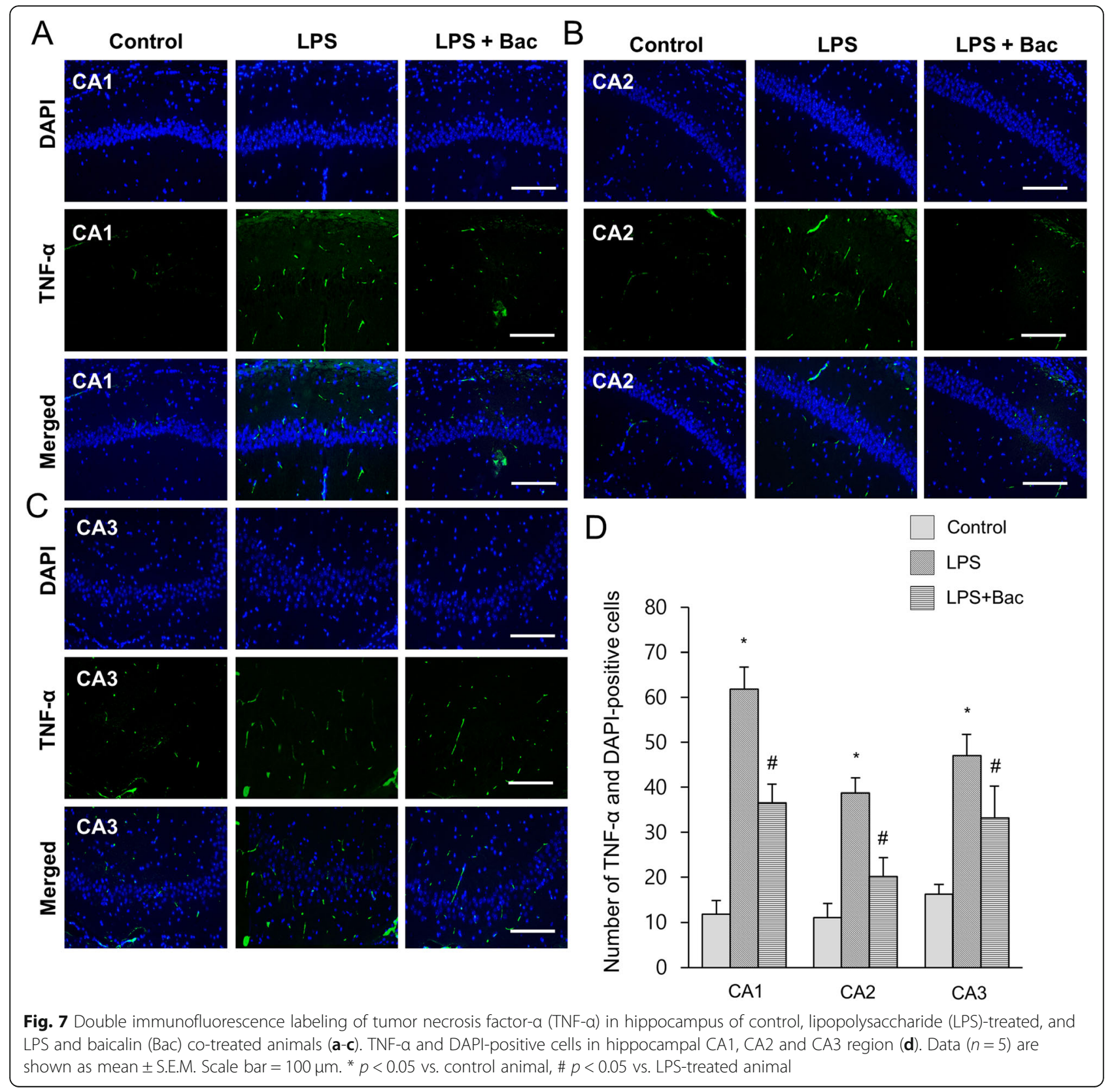

hippocampus. Baicalin mitigated neuroinflammation in the hippocampus caused by LPS treatment by regulating IL-1 $\beta$ expression. TNF- $\alpha$ is a potent inflammatory mediator that has an essential role in the inflammatory system. TNF- $\alpha$ is responsible for cytokine production, adhesion molecule expression, and growth stimulation [40]. TNF- $\alpha$ expression is upregulated in arthritis caused by LPS treatment [41]. Furthermore, LPS increased TNF- $\alpha$ levels in mouse neuronal cells [42]. Our results were in agreement with previous studies. Increased TNF- $\alpha$ expression was observed in the LPS-treated hippocampus and alleviated with baicalin co-treatment. Baicalin mitigated LPS-induced upregulation of NF- $\mathrm{kB}$ expression and inflammatory cytokines including IL-1 $\beta$ and TNF- $\alpha$. In addition, baicalin suppressed the inflammatory response by preventing overactivation of microglia and astrocytes, regulating NF- $\mathrm{kB}$ expression and the inflammatory cytokines, IL- $1 \beta$ and TNF- $\alpha$.

Hippocampal CA1 region is a sensitive area that responds to LPS stimuli [43]. Administration of LPS induces changes in synaptic transmission and plasticity in the hippocampal CA1 region [44]. In addition, superoxide induces selective vulnerability of the hippocampal CA1 region to damage, a more vulnerable area than CA3 region [45]. Immunofluorescence staining showed changes in Iba- 1 , GFAP, NF-kB, IL- $1 \beta$, and TNF- $\alpha$ 
expression were more significantly increased in the CA1 region of LPS-treated animals than in the CA2 and CA3 regions. This study elucidated that baicalin attenuates LPS-induced inflammatory response by modulating microglia and astrocyte activation and inhibiting NF- $\mathrm{kB}$ expression and suppressing IL- $1 \beta$ and TNF- $\alpha$ expression in hippocampus.

\section{Conclusions}

Our results showed that baicalin alleviates LPS-induced inflammatory response in the hippocampus by suppressing NF- $\mathrm{kB}$ associated with the inflammatory response. These results provide an evidence that baicalin modulates LPSinduced neuroinflammation in hippocampus of adult mice. Our finding also suggest the fact that baicalin has a potential therapeutic application for treating neuroinflammation.

\begin{abstract}
Abbreviations
DAPI: 4', 6-Diamidino-2-phenylindole; FITC: Fluorescein isothiocyanate; GFAP: Glial fibrillary acidic protein; Iba-1: Ionized calcium binding adaptor molecule-1; IL-1 B: Interleukin-1 $\beta$; LPS: Lipopolysaccharide; NBP: Neutral buffered paraformaldehyde; NF-kB: Nuclear factor-kappa B; PBS: Phosphatebuffered saline; TBST: Tris-buffered saline containing 0.1\% Tween-20; TNFa: Tumor necrosis factor-a
\end{abstract}

\section{Acknowledgements}

Not applicable.

\section{Authors' contributions}

M-AS, D-JP, and J-BK performed experiment, organized and analyzed data. M-OK designed the experiment and analyzed data. P-OK designed the experiment, wrote and corrected the manuscript, and managed general research and drafting. All authors read and approved this final manuscript.

\section{Funding}

This research was supported by the National Research Foundation of Korea (NRF) grant funded by the Korea government (MEST)(NRF-

2018R1D1A1B07044074).

\section{Availability of data and materials}

The data that support the findings of this study are available on request from the corresponding author on reasonable request.

\section{Competing interests}

The authors declare that there is no financial conflict of interests to publish these results.

\section{Author details}

${ }^{1}$ Department of Anatomy, College of Veterinary Medicine, Research Institute of Life Science, Gyeongsang National University, 501 Jinjudaero, Jinju 52828, South Korea. ${ }^{2}$ Division of Life Science and Applied Life Science, College of Natural Sciences, Gyeongsang National University, 501 Jinjudaero, Jinju 52828, South Korea.

Received: 31 May 2020 Accepted: 27 July 2020

Published online: 17 September 2020

\section{References}

1. Raetz CRH, Whitfield C. Lipopolysaccharide endotoxins. Annu Rev Biochem. 2002;71:635-700.

2. Zhao J, Bi W, Xiao S, Lan X, Cheng X, Zhang J, Lu D, Wei W, Wang Y, Li H, Fu Y, Zhu L. Neuroinflammation induced by lipopolysaccharide causes cognitive impairment in mice. Sci Rep. 2019;9(1):5790.

3. Liu M, Bing G. Lipopolysaccharide animal models for Parkinson's disease. Parkinsons Dis. 2011;2011:327089.
4. Hamesch K, Borkham-Kamphorst E, Strnad P, Weiskirchen R. Lipopolysaccharide-induced inflammatory liver injury in mice. Lab Anim. 2015;49(1 Suppl):37-46.

5. Kim KH, Kwun MJ, Han CW, Ha KT, Choi JY, Joo M. Suppression of lung inflammation in an LPS-induced acute lung injury model by the fruit hull of Gleditsia sinensis. BMC Complement Altern Med. 2014;14:402.

6. Charo IF, Ransohoff RM. The many roles of chemokines and chemokine receptors in inflammation. N Engl J Med. 2006;354(6):610-21.

7. Zhang JM, An J. Cytokines, inflammation, and pain. Int Anesthesiol Clin. 2007:45(2):27-37.

8. Quan N, Stern EL, Whiteside MB, Herkenham M. Induction of proinflammatory cytokine mRNAs in the brain after peripheral injection of subseptic doses of lipopolysaccharide in the rat. J Neuroimmunol. 1999; 93(1-2):72-80.

9. Na KS, Jung HY, Kim YK. The role of pro-inflammatory cytokines in the neuroinflammation and neurogenesis of schizophrenia. Prog NeuroPsychopharmacol Biol Psychiatry. 2014;48:277-86.

10. Smith JA, Das A, Ray SK, Banik NL. Role of pro-inflammatory cytokines released from microglia in neurodegenerative diseases. Brain Res Bull. 2012; $87(1): 10-20$

11. Li HB, Chen F. Isolation and purification of baicalein, wogonin and oroxylin A from the medicinal plant Scutellaria baicalensis by high-speed countercurrent chromatography. J Chromatogr A. 2005;1074(1-2):107-10.

12. Cheng O, Li Z, Han Y, Jiang Q, Yan Y, Cheng K. Baicalin improved the spatial learning ability of global ischemia/reperfusion rats by reducing hippocampal apoptosis. Brain Res. 2012;1470:111-8.

13. Li BQ, Fu T, Gong WH, Dunlop N, Kung H, Yan Y, Kang J, Wang JM. The flavonoid baicalin exhibits anti-inflammatory activity by binding to chemokines. Immunopharmacology. 2000;49(3):295-306.

14. Martínez Medina JJ, Naso LG, Pérez AL, Rizzi A, Ferrer EG, Williams PAM. Antioxidant and anticancer effects and bioavailability studies of the flavonoid baicalin and its oxidovanadium (IV) complex. J Inorg Biochem. 2017;166:150-61.

15. Dong SJ, Zhong YQ, Lu WT, Li GH, Jiang HL, Mao B. Baicalin inhibits lipopolysaccharide-induced inflammation through signaling NF-KB pathway in HBE16 airway epithelial cells. Inflammation. 2015;38(4):1493-501.

16. Krakauer $T$, Li BQ, Young $H A$. The flavonoid baicalin inhibits superantigeninduced inflammatory cytokines and chemokines. FEBS Lett. 2001;500(1-2): $52-5$.

17. Bai C, Li T, Sun Q, Xin Q, Xu T, Yu J, Wang Y, Wei L. Protective effect of baicalin against severe burn-induced remote acute lung injury in rats. Mol Med Rep. 2018;17(2):2689-94.

18. Wang $Y$, Jia $Y$, Yang $X$, Liang B, Gao H, Yang T. A potential role of Baicalin to inhibit apoptosis and protect against acute liver and kidney injury in rat preeclampsia model. Biomed Pharmacother. 2018;108:1546-52.

19. Chen Z, Jalabi W, Shpargel KB, Farabaugh KT, Dutta R, Yin X, Kidd GJ, Bergmann CC, Stohlman SA, Trapp BD. Lipopolysaccharide-induced microglial activation and neuroprotection against experimental brain injury is independent of hematogenous TLR4. J Neurosci. 2012;32(34):11706-15.

20. Lieberman AP, Pitha PM, Shin HS, Shin ML. Production of tumor necrosis factor and other cytokines by astrocytes stimulated with lipopolysaccharide or a neurotropic virus. Proc Natl Acad Sci U S A. 1989;86(16):6348-52.

21. Ye C, Li S, Yao W, Xu L, Qiu Y, Liu Y, Wu Z, Hou Y. The anti-inflammatory effects of baicalin through suppression of NLRP3 inflammasome pathway in LPSchallenged piglet mononuclear phagocytes. Innate Immun. 2016;22(3):196-204.

22. Buttini M, Mir A, Appel K, Wiederhold KH, Limonta S, Gebicke-Haerter PJ, Boddeke HW. Lipopolysaccharide induces expression of tumour necrosis factor alpha in rat brain: inhibition by methylprednisolone and by rolipram. Br J Pharmacol. 1997:122(7):1483-9.

23. Jacque CM, Vinner C, Kujas M, Raoul M, Racadot J, Baumann NA. Determination of glial fibrillary acidic protein (GFAP) in human brain tumors. J Neurol Sci. 1978:35(1):147-55.

24. Ito D, Imai Y, Ohsawa K, Nakajima K, Fukuuchi Y, Kohsaka S. Microgliaspecific localisation of a novel calcium binding protein, Iba1. Brain Res Mol Brain Res. 1998;57(1):1-9.

25. Sasaki Y, Ohsawa K, Kanazawa H, Kohsaka S, Imai Y. Iba1 is an actin-crosslinking protein in macrophages/microglia. Biochem Biophys Res Commun. 2001;286(2):292-7.

26. Liedtke W, Edelmann W, Bieri PL, Chiu FC, Cowan NJ, Kucherlapati R, Raine CS. GFAP is necessary for the integrity of CNS white matter architecture and long-term maintenance of myelination. Neuron. 1996;17(4):607-15. 
27. Fujiwara N, Kobayashi K. Macrophages in inflammation. Curr Drug Targets Inflamm Allergy. 2005;4(3):281-6.

28. Silswal N, Singh AK, Aruna B, Mukhopadhyay S, Ghosh S, Ehtesham NZ. Human resistin stimulates the pro-inflammatory cytokines TNF-alpha and IL12 in macrophages by NF-kappaB-dependent pathway. Biochem Biophys Res Commun. 2005;334(4):1092-101.

29. Hoesel B, Schmid JA. The complexity of NF-KB signaling in inflammation and cancer. Mol Cancer. 2013;12:86.

30. Albrecht U, Yang X, Asselta R, Keitel V, Tenchini ML, Ludwig S, Heinrich PC, Häussinger D, Schaper F, Bode JG. Activation of NF-kappaB by IL-1 beta blocks IL-6-induced sustained STAT3 activation and STAT3-dependent gene expression of the human gamma-fibrinogen gene. Cell Signal. 2007;19(9): 1866-78.

31. Hayden MS, Ghosh S. Regulation of NF-kB by TNF family cytokines. Semin Immunol. 2014;26(3):253-66.

32. Frost RA, Nystrom GJ, Lang CH. Lipopolysaccharide regulates proinflammatory cytokine expression in mouse myoblasts and skeletal muscle. Am J Physiol Regul Integr Comp Physiol. 2002;283(3):698-709.

33. Garlanda C, Dinarello CA, Mantovani A. The interleukin-1 family: back to the future. Immunity. 2013;39(6):1003-18.

34. Ren $\mathrm{K}$, Torres R. Role of interleukin-1 beta during pain and inflammation. Brain Res Rev. 2009:60(1):57-64.

35. Makó V, Czúcz J, Weiszhár Z, Herczenik E, Matkó J, Prohászka Z, Cervenak L. Proinflammatory activation pattern of human umbilical vein endothelial cells induced by IL-1 $\beta$, TNF-a, and LPS. Cytometry A. 2010;77(10):962-70.

36. Li M, Li C, Yu H, Cai X, Shen X, Sun X, Wang J, Zhang Y, Wang C. Lentivirusmediated interleukin-1 beta (IL-1 beta) knock-down in the hippocampus alleviates lipopolysaccharide (LPS)-induced memory deficits and anxietyand depression-like behaviors in mice. J Neuroinflammation. 2017;14(1):190.

37. Schneider H, Pitossi F, Balschun D, Wagner A, del Rey A, Besedovsky HO. A neuromodulatory role of interleukin-1 beta in the hippocampus. Proc Natl Acad Sci U S A. 1998;95(13):7778-83.

38. Sheppard O, Coleman MP, Durrant CS. Lipopolysaccharide-induced neuroinflammation induces presynaptic disruption through a direct action on brain tissue involving microglia-derived interleukin 1 beta. J Neuroinflammation. 2019;16(1):106.

39. Tong L, Balazs R, Soiampornkul R, Thangnipon W, Cotman CW. Interleukin-1 beta impairs brain derived neurotrophic factor-induced signal transduction. Neurobiol Aging. 2008;29(9):1380-93.

40. Rothe J, Gehr G, Loetscher H, Lesslauer W. Tumor necrosis factor receptors-structure and function. Immunol Res. 1992;11(2):81-90.

41. Merrill JC, You J, Constable C, Leeman SE, Amar S. Whole-body deletion of LPS-induced TNF-a factor (LITAF) markedly improves experimental endotoxic shock and inflammatory arthritis. Proc Natl Acad Sci U S A. 2011; 108(52):21247-52.

42. Gahring LC, Carlson NG, Kulmar RA, Rogers SW. Neuronal expression of tumor necrosis factor alpha in the murine brain. Neuroimmunomodulation. 1996:3(5):289-303.

43. Espinosa-Oliva AM, de Pablos RM, Villarán RF, Argüelles S, Venero JL, Machado A, Cano J. Stress is critical for LPS-induced activation of microglia and damage in the rat hippocampus. Neurobiol Aging. 2011;32(1):85-102.

44. Commins S, O'Neill LA, O'Mara SM. The effects of the bacterial endotoxin lipopolysaccharide on synaptic transmission and plasticity in the CA1subiculum pathway in vivo. Neuroscience. 2001;102(2):273-80.

45. Wilde GJ, Pringle AK, Wright P, lannotti F. Differential vulnerability of the CA1 and CA3 subfields of the hippocampus to superoxide and hydroxyl radicals in vitro. J Neurochem. 1997;69(2):883-6.

\section{Publisher's Note}

Springer Nature remains neutral with regard to jurisdictional claims in published maps and institutional affiliations.

Ready to submit your research? Choose BMC and benefit from:

- fast, convenient online submission

- thorough peer review by experienced researchers in your field

- rapid publication on acceptance

- support for research data, including large and complex data types

- gold Open Access which fosters wider collaboration and increased citations

- maximum visibility for your research: over $100 \mathrm{M}$ website views per year

At BMC, research is always in progress.

Learn more biomedcentral.com/submissions 